\title{
Publicar contos de fadas na Velha República: um compromisso com a nação ${ }^{1}$
}

\author{
Andréa Borges Leão \\ Doutora em Sociologia pela Universidade de São Paulo, professora e pesquisadora \\ do Programa de Pós-Graduação em Educação Brasileira, da Faculdade de Educação da \\ Universidade Federal do Ceará. \\ E-mail: dealeao@secrel.com.br
}

Os livreiros franceses que se instalaram no Brasil do século XIX foram os primeiros comerciantes a colocar à disposição das famílias coleções de livros especialmente destinados à diversão e instrução de crianças e jovens. $\mathrm{O}$ princípio norteador desse comércio foi a vocação exportadora do mercado do livro francês e, em conseqüência, o intenso movimento das trocas culturais iniciado pela circulação internacional dos textos.

Essas operações, aliadas a uma política de distribuição baseada na disseminação de pontos de venda pela América Latina, ensejaram a transferência de capital literário para o mercado de livros nos países de produção ainda incipiente. O que poderia ser um projeto de colonização cultural, de simples imposição de bens de consumo, acabou permitindo o acúmulo de um patrimônio necessário à autonomia da literatura nacional, já em vias de constituição.

A família Garnier foi pioneira na criação de um mercado para o livro infantil no Brasil, e seu projeto intelectual permitiu a consolidação de uma cultura literária para a nossa infância e juventude. Os livros importados vendidos na Livraria Garnier e, posteriormente, traduzidos e adaptados por autores brasileiros, são marcados por uma expressiva longevidade, prova de vigor que pode levar à preferência tanto do público adulto que escolhe livros para crianças quanto dos próprios leitores. O repertório de clássicos europeus, como Telêmaco, de Fénelon, Aventuras de Robinson Crusoé, de Daniel Defoe, e os Contos, de Charles Perrault, permanece há longos anos nos catálogos das casas editoras voltadas ao entretenimento e à instrução infantil ${ }^{2}$.

Porém, os caminhos da literatura infantil brasileira começaram mesmo a ser delineados quando houve reação ao comércio do livro importado. A partir dos anos de 1890, Pedro da Silva Quaresma, comerciante de livros populares do Rio de Janeiro, iniciou um movimento de nacionalização do livro de literatura infantil. Diante do que argumentava ser a desigualdade entre o universo

1. Este artigo é parte da tese Brasil em imaginação: livros, impressos e leituras infantis (1890-1915), defendida no Programa de Pós-Graduação em Sociologia, da Universidade de São Paulo, em setembro de 2002, e que permanece inédita em livro. Vincula-se, ainda, à pesquisa que desenvolvo sobre as traduções e adaptações dos clássicos da literatura infantil francesa no Brasil.

2. Ver LEÃO, Andréa. Universos da devoção, sabedoria e moral: as Bibliotecas Juvenis Garnier. Educação em Revista, Minas Gerais, Universidade Federal de Minas Gerais/ Faculdade de Educação, n. 43, jun. 2006. 
comunicação \& educação • Ano XII • Número 3 • set/dez 2007

lingüístico dos textos traduzidos do francês para o português de Portugal e o das crianças brasileiras, Quaresma encomendou ao romancista Alberto de Figueiredo Pimentel a compilação dos contos que andavam dispersos na tradição oral brasileira, não em um só livro, mas em toda uma coleção escrita na linguagem cotidiana. Para tanto, soube aproveitar os pequenos espaços de discussão que antecedem às histórias, escrevendo ele mesmo os prefácios e as notas aos leitores, nos quais realçava o prestígio literário e a tarefa pedagógica de Pimentel diferença marcante em relação a seus concorrentes. Convidou o artista Julião Machado para ilustrar as obras, reconhecendo a importância da nova produção para a formação do gosto cultural dos jovens brasileiros. Os livros da coleção Quaresma pretendiam fazer da leitura uma diversão, do conhecimento um recreio e da moral uma disposição íntima.

No dia 14 de abril de 1894, foi publicado o primeiro volume da Biblioteca Infantil da Livraria Quaresma: o livro Histórias da Carochinha. Logo após, surgiriam Histórias da Avozinha (1896), Histórias da Baratinha (1896), Histórias do Arco da Velha, Histórias de Fada, Contos do Tio Alberto, Os Meus Brinquedos, Teatrinho Infantil, O Álbum das Crianças, Castigo de um Anjo e O Livro das Crianças.

O tino comercial do editor era tanto que, para ampliar a difusão de suas edições, ele fez uma parceria com as casas Edson: quem comprasse os livros de modinhas ao violão de Catulo da Paixão Cearense podia tanto lê-los como escutá-los nos gramofones à venda. O comerciante fluminense estabilizou seu catálogo anexando às páginas de suas brochuras populares o anúncio das bibliotecas para crianças. Assim, obras como o Dicionário das Flores, Folhas e Frutos e Histórias Populares da Princesa Magalona davam publicidade aos títulos infantis.

Daí em diante, ao lado das funções tradicionais de formação moral e instrução recreativa, o livro de literatura infantil adquiria mais duas atribuições de modo algum inconciliáveis: uma comercial, nos termos da criação de um público de massas, e outra afetiva, ao promover uma legitimidade emocional e identificar os leitores com um sentimento de pertença ao mundo das letras e à nação brasileira.

A produção para crianças tornava-se objeto do que veio a ser uma nova onda nacionalista, e os livros, suportes de imagens que, retiradas do mundo da fantasia, não desconheciam o compromisso com o mercado. Um campo literário ia se formando ao mesmo tempo em que surgiam as primeiras estratégias dos livreiros-editores, com vistas à afirmação e ao reconhecimento de suas atividades.

Este artigo objetiva traçar o percurso que possibilita a passagem da história da edição a uma história da produção literária infantil. A preocupação com a definição do gênero relacionado às classes de idade foi, antes de tudo, tarefa dos livreiros-editores. Eram eles que classificavam e distribuíam os textos, contratavam tradutores ou simplesmente orientavam a recolha das narrativas populares, organizando-as em coleções ou bibliotecas.

Para tanto, é necessário um trabalho de renovação das fontes documentais de que lança mão a historiografia literária, considerando um método de análise 
que parta do circuito de produção e circulação dos livros, tornando-os suportes das escolhas editoriais, da escrita dos textos e da apropriação criativa. Aí temos o projeto intelectual de Roger Chartier: manejar ao mesmo tempo a crítica textual, a sociologia dos atores envolvidos na produção, o exame formal dos suportes e o estudo das representações e práticas da leitura ${ }^{3}$. Para conhecer a gênese e a formação da literatura infantil brasileira, é necessária, antes de tudo, a análise das condições de produção, transmissão e recepção dos textos.

\section{O MERCADO DE EDIÇÃO INFANTIL NA VELHA REPÚBLICA}

Ler com devoção A Cruz de Madeira e os Meninos Perdidos, sofrer com as lições tomadas por Henrique D'Eichenfels, no opúsculo que narra sua história, encher os olhos com as gravuras da coleção de livros $O$ Carneirinho, A Mosca e Os Ovos de Páscoa, todos de autoria do cônego Christoph Von Schmid, só foi possível porque o francês Baptiste-Louis Garnier, ao conhecer a identificação dos brasileiros com a cultura européia, e do hábito de consumo de objetos importados e de idéias importadas, contratou, em 1870, o escritor Nuno Álvares Pereira de Sousa para um trabalho de tradução e adaptação, a fim de compor o repertório de sua Biblioteca Infantil. A coletânea de histórias do cônego Schmid advinha toda da tradição popular alemã do século XVIII, como a dos irmãos Grimm. Ao oferecer à meninada textos e imagens distantes, Nuno Álvares reservava um mercado para o trabalho literário, pessimamente remunerado, e inventava um consumo, quer dizer, um novo filão de mercado.

Os modelos de identificação trazidos nos livros de Madame Le Prince de Beaumont, como O Bazar das Crianças ou Diálogos de uma Sábia Preceptora com suas Discípulas, devem igualmente em muito ter tocado o sentimento aristocrático das crianças, aprendizes da língua e educação francesas, leitoras de catecismos, cujo universo mental correspondia à simbologia que os adultos forjavam para o Império do Brasil. Para que esses livros, cheios de cromos e estampas coloridas, fossem lidos, era necessário que criassem uma reciprocidade entre o enredo de suas histórias e o gosto e estilo de vida nacional. Ao lado de Nuno Álvares, eram famosas as adaptações de Branca de Vila Flor, como A Fonte das Pérolas e Outros Contos de Fadas, ou de Pinheiro Chagas, Ramiz Galvão e Teófilo Braga, como as Fábulas de La Fontaine. Ramiz Galvão também verteu opúsculos de títulos religiosos, como A Novena da Candelária, de Charles Nodier.

Note-se que o movimento de tradução e adaptação dos livros infantis ao gosto da meninada brasileira revela o quanto essa prática significava de reação ao livro importado. O Barão de Paranapiacaba, organizador de nossa primeira Biblioteca Escolar, criada pelo Conselho de Instrução do Império ${ }^{4}$, além de escolher os livros a serem adotados nas escolas, já se tornara conhecido pelas traduções das Fábulas de La Fontaine, publicadas em 1886 pela Imprensa Oficial.

Daí para o movimento de nacionalização do livro infantil foi um passo. Figueiredo Pimentel fazia muito barulho e sucesso comercial com os chamados livros proibidos, romances de temas picantes, do tipo $O$ Aborto e o Terror
3. Do autor, ver História cultural: entre práticas e representações. Rio de Janeiro: Difel, 1990.

4. ARROYO, Leonardo. Literatura infantil brasileira. São Paulo: Melhoramentos, 1990. 
comunicação \& educação • Ano XII • Número 3 • set/dez 2007

dos Maridos. Talvez como saída moral, o escritor tenha aceitado reunir a série de contos infantis para a Livraria Quaresma, que, aproveitando-se do êxito editorial da fórmula européia dos contos de fadas, decidira inventar o gênero brasileiro, ora publicando as obras de Grimm e Perrault reescritas com tintas de cores locais, ora organizando em texto as narrativas populares. A Biblioteca Infantil da Livraria do Povo compunha-se de brochuras de pequeno formato, assemelhando-se mais a folhetos de cordel; todas, porém, encapadas com cromos e gravuras. Os Contos da Carochinha, as Histórias da Avozinha e as Histórias da Baratinha alcançaram grande êxito entre a criançada, e sucessivas tiragens para Pedro da Silva Quaresma.

Mas a gênese dessa produção de bens culturais de massa coincidia com o empenho dos escritores na formação da alma do brasileiro. Não em relação aos livros escolares de conteúdo patriótico, como os de Olavo Bilac e Coelho Neto, mas a uma produção que fazia da leitura um momento de construção de categorias de percepção e organização conceitual do mundo, unificando as crianças numa comunidade de imaginação nacional. Ora, com o novo regime republicano, urgia a formação de leitores capazes de acompanhar o crescimento do Brasil.

Quando o livreiro Francisco Alves ofereceu, em 1906, sua coleção de livros clássicos - A Casa do Saltimbanco, As Férias, Os Desastres de Sofia e As Meninas Exemplares; o primeiro de Madame de Stolz, e os três últimos das primeiras traduções da famosa escritora francesa Sophie de Ségur - como $4^{\circ}, 5^{\circ}$, $7^{\circ}$ e 8o prêmios ao concurso "F" do Semanário $O$ Tico-Tico ${ }^{5}$, não apenas contava ampliar a difusão de seu estoque, mas confirmava a existência de um público já formado que, ao lado dos brinquedos, em muito se empenharia em vencer para ganhar livros de presente.

\section{A INVENÇÃO DA BIBLIOTECA INFANTIL QUARESMA}

Pedro da Silva Quaresma esmerava-se na apresentação das capas, inaugurando um estilo ornamental de edição. Ardia nos olhos a quantidade de enfeites e penduricalhos das formas gráficas e, nos catálogos, as obras vinham, na maioria das vezes, indicadas pelo número de páginas. As edições Quaresma valiam o quanto pesavam e se sobressaíam pelo trabalho artístico.

O livreiro também sabia aproveitar as operações de um prefácio, com as quais buscava a consagração dos cantores de violão, dos palhaços de circo, das doceiras e velhas cozinheiras e dos poetas menores. Nos regimes prefaciais, locais de transação, Quaresma usava de muita argúcia para transferir o que detinha de capital simbólico, contribuindo para a construção do sentido das obras. Os tipos novos e as letras de fantasia, as milhares de vinhetas e gravuras, o esmero na qualidade do papel, as capas litografadas e coloridas, as notas e advertências que escrevia de próprio punho, o recurso a cartas de renomados

5. Semanário O Tico-Tico, quarta-feira, 7 fev. 1906. intelectuais, como a apresentação do Florilégio dos Cantores, de Catulo da Paixão 
Cearense, são o exemplo mais acabado das intervenções e estratégias editoriais de Quaresma. Suas edições eram vendidas nos circos de cavalinhos, nas festas e feiras, nas ruas, nas calçadas.

Nos livros infantis, Pimentel tinha como única preocupação a fidelidade à transcrição direta da fala. Nem ele nem Quaresma se empenharam em oferecer esmeradas composições literárias. As narrativas fluentes na tradição oral - as crianças de todos os países sabiam de cor -, encontravam sua forma literária através de uma escrita solta, inteiramente fora das regras da gramática e das preocupações com o estilo.

Foi assim que entre primeiro e 13 de março de 1894, Figueiredo aprontou os textos com 61 contos recolhidos. Julião Machado foi chamado para desenhálos e, um mês depois, em 14 de abril, os Contos da Carochinha conheciam a luz da Rua de São José, endereço da Livraria Popular de Pedro da Silva Quaresma. Logo viriam outros volumes; muitos outros. O livreiro comprou briga com os críticos espavoridos, caprichou nas explicações e advertências. Em paga, Figueiredo Pimentel vendeu-lhe todos os direitos de propriedade.

Os Contos da Carochinha destinavam-se à esposa do autor, Maria de Santana, atendendo aos pedidos para que escrevesse algumas novelas pequenas de leitura noturna, boas para a conciliação do sono. Em todos os livros, Figueiredo utilizou os mesmos protocolos. O Álbum das Crianças, livro de poesias, ofertou aos meninos Raul, Roberto, Renato, Romelia, Rachel e Riza, filhos do parteiro dr. Henrique Rodolfo Baptista. O Castigo de um Anjo, de 1897, impresso no Rio de Janeiro, na Tipografia Montenegro da Rua do Ouvidor, Figueiredo dedicou aos pequeninos Custódio e Olga, filhos de Quaresma.

O vínculo imaginado de dependência ao destinatário fortalecia o pacto de credibilidade entre a intencionalidade do autor e as expectativas do leitor. Em 1898, quando J. G. de Azevedo publicou Histórias de Fadas, uma coleção de contos populares orientada também por Figueiredo Pimentel, a oferta foi feita pelo próprio autor à "Ilustrada Redacção da Gazeta de Notícias".

Desse modo, Figueiredo oferecia sua decisiva contribuição para a invenção da literatura infantil brasileira. A partir de 1907, no escritório da Gazeta de Notícias, inaugura uma coluna social chamada Binóculo. As senhoras, os escritores, os políticos, os cavalheiros, as roupas, nada se furtava ao crivo do cronista mundano. Longe dos tempos dos livros de escândalo, Figueiredo já era autor consagrado no mercado das letrinhas e as crianças não escapariam às suas lentes de aumento.

Com a publicação da Biblioteca Infantil, Quaresma e Pimentel possibilitaram a conservação de uma prática literária ligada à oralidade (os contos populares), em um suporte da escrita (os livros). Para falar com os leitores, o romancista assumiu a responsabilidade de entrar na pele das contadoras de histórias: as baratinhas. Essas foram as condições para que o novo gênero criasse a sua própria recepção, como foi o caso da prática de leitura do menino Batão, relatada no número 83 do semanário infantil O Tico-Tico, no ano de 1907. 
comunicação \& educação • Ano XII • Número 3 • set/dez 2007

\section{OS EFEITOS DOS LIVROS DA CAROCHINHA}

Sebastião Lopes da Fonseca nasceu no dia 25 de julho de 1902. Aos vinte dias, ficou órfão da mãe, dona Zulmira, contingência pela qual o pai, Luiz Manoel da Fonseca, confiou-o aos cuidados da tia materna, dona Maria Lopes de Melo, esposa do funcionário público João de Souza Melo. Em casa, chamavam-no Batão. Dele, dona Maria contou que desde cedo revelara dotes extraordinários para assuntos que puxassem pela inteligência. Os Lopes de Melo residiam em São Domingos de Niterói.

Acreditava-se que a mecânica dos engenhos comandava a alma de Sebastião Lopes da Fonseca. Em 1907, aos quatro anos e meio, o menino lia os contos de fadas no Tico-Tico sem ainda saber ler. Os editores compararam-no a um autômato e sua prática de leitura, a um fenômeno de ilusionismo, a um teatro animado como os espetáculos de marionetes das feiras e circos de cavalinhos. Para eles, o menino engolira uma placa de fonógrafo ${ }^{6}$. O retrato de Sebastião foi estampado à vista de todos e recebeu como legenda: Os effeitos d'O Tico-Tico - um menino-prodígio.

Em uma tarde de maio de 1907, dona Maria deixou as costuras, tomou a barca, deslizou pelas águas da baía, desceu no cais e, enfim, pousou na Rua do Ouvidor. Não foi para fazer compras. Dessa vez, saíra à passarela da moda acompanhada de Batão, que já contava quatro anos e meio. Iam os dois com propósito firme: o número 132. Entraram no escritório do Malho, sede do Tico-Tico. O pessoal da redação já os esperava. O motivo da visita era bem outro: podia tratar-se de mais um prodígio do avanço técnico, mais um artifício ilusionista como as máquinas falantes chamadas fonógrafos. O caso beirava o extraordinário, quer dizer, Batão lia de cor e salteado as histórias da carochinha do Tico-Tico sem sequer conhecer as letras do alfabeto. Batão tornara-se um boneco animado e falante.

O menino revelara seus dotes extraordinários após o aparecimento do TicoTico. Batão sentia-se fascinado pelas histórias da carochinha que enchiam as páginas do semanário. Naquela tarde, entrou no escritório da Rua do Ouvidor na maior algazarra. Encantou o pessoal da redação, passeou de colo em colo e com uma vozinha fina e estridente de caixinha de música, antes de provar ao que vinha, cobrou o prometido: só demonstraria seu dom se lhe dessem o cavalinho. Fez-se a experiência, enfim, que foi repetida diversas vezes. A fim de baralhar os mecanismos da mente prodigiosa de Batão, deram-lhe uma historinha mais complicada, de vinte e quatro quadrinhos. Leu do mesmo modo. Em seguida, fizeram-lhe ler apontando as estampas salteadamente. Mas de nada adiantaram esses truques e dificuldades. Batão impostou a vozinha, pôs-se em posição de

6. Antigo aparelho destinado a registrar e a reproduzir os sons da voz humana, representando, originalmente, o aparelho inventado por Thomas A. Edison (1847-1931, físico norte-americano), em 1878. (N.E.) sentido, perfilou sua figura de quatro anos e meio, modulou com precisão as inflexões da narrativa e leu tudo.

Dona Maria trazia na bolsa dois retratos. No primeiro, aparecia toda a família em um quadro entre decoroso e didático. Papai sentado, pernas cruzadas, braço apoiado na cadeira, bigodeira em riste. Mamãe, representada de corpo inteiro, entre papai e Batão, com o braço enlaçando o pequeno prodigioso. Batão vinha 


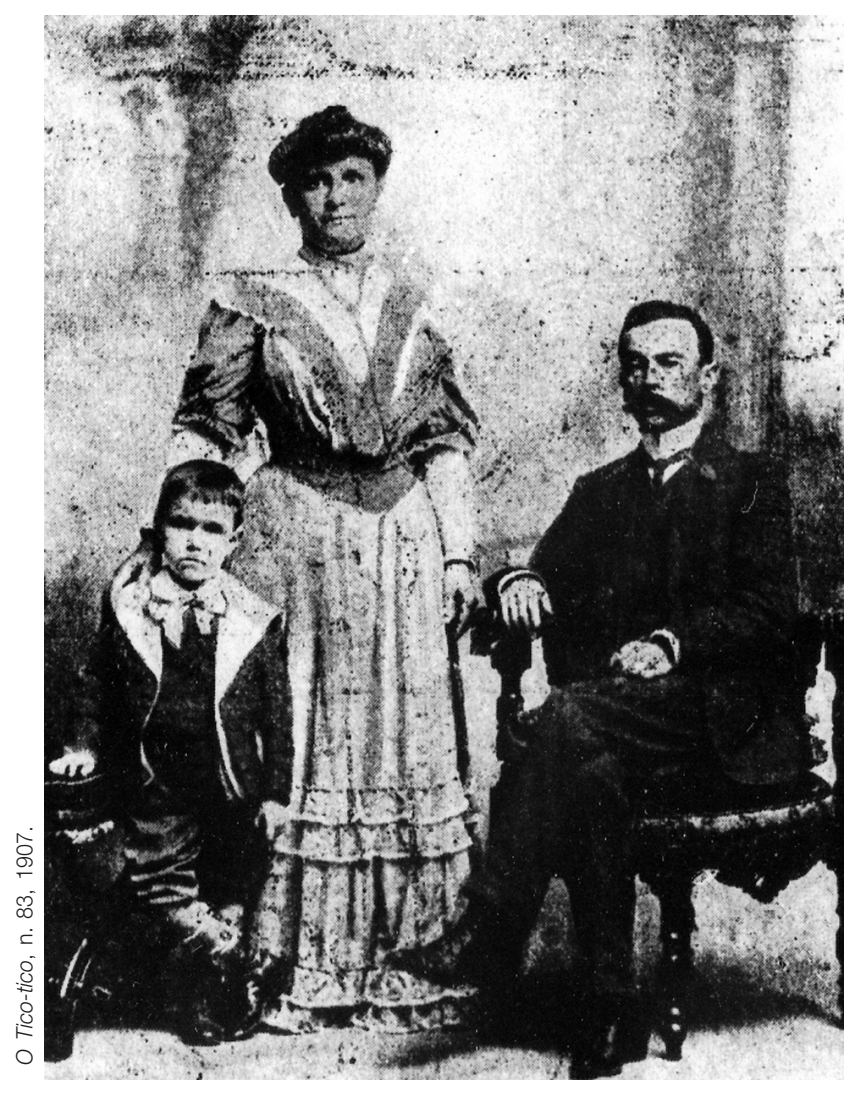

em pose de choro, a boca em arco, as perninhas cruzadas e elegantemente apertado no paletó. Pendia-lhe da gola uma gravata de laçarote.

$\mathrm{O}$ outro retrato representava a cena da leitura. Precisava ser tão fiel a ponto de dar ao quadro uma ilusão de vida. Batão, entre o móvel da sala e um cachorrinho, trazia entre as mãos um número do TicoTico. Mamãe e papai criavam um significado para a prática de leitura do filho. Por isso, puseram-no a olhar fixo, em nova pose, elegante e artificial, o semanário pendendo a exibir os quadrinhos das histórias; toda a cena em muito contribuindo para a produção dos efeitos ilusionistas.

Batão lia o Tico-Tico sem saber ler graças à estrutura narrativa dos contos de fadas, que facilitava a memorização dos eventos e personagens para a recitação; daí repetir o que a palavra adulta nele já imprimira. O que se passou naquela tarde de maio foi a prática da memorização de fórmulas ensinadas oralmente, de todo conhecidas do público infantil. Além do que, um leitor não é obrigado a ler uma história da frente para trás, acompanhar as linhas e figuras da esquerda para a direita; por isso, o pequeno desvendou a mistura dos quadrinhos ${ }^{7}$.

Em razão do trabalho de difusão levado a cabo por

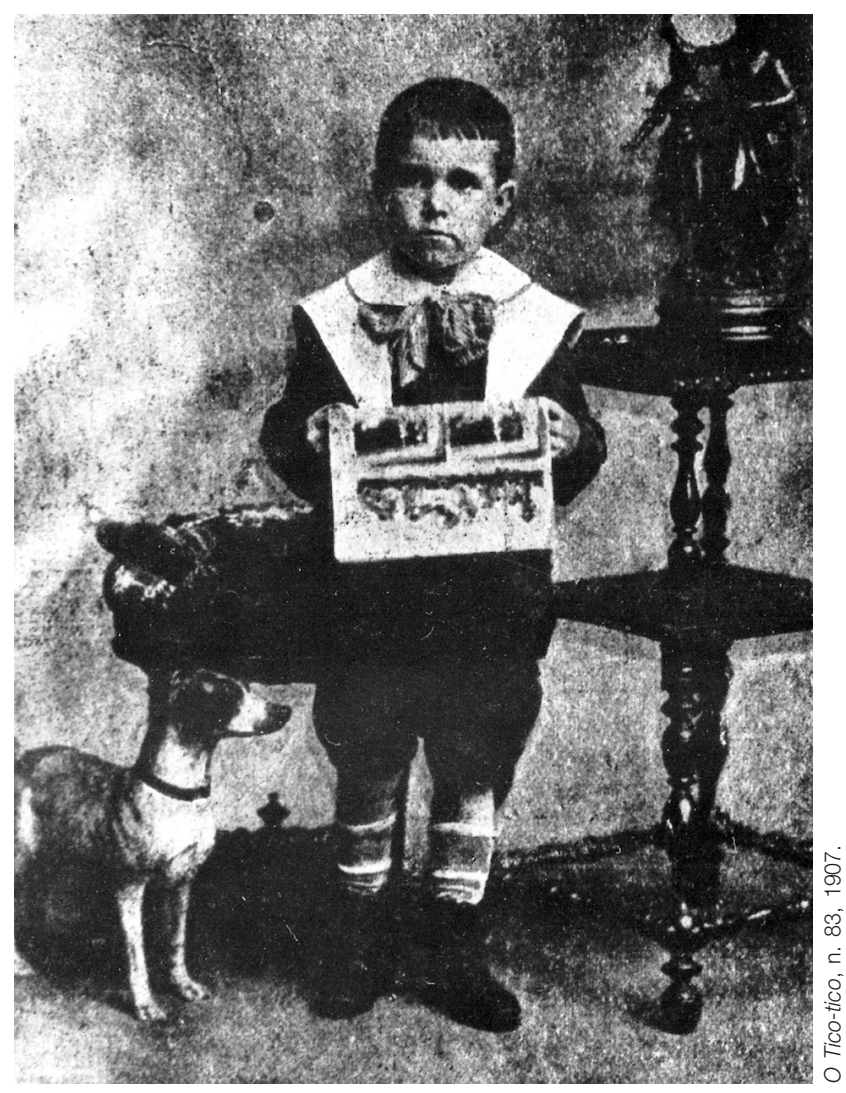

7. Sobre o autodidatismo na leitura, ler: HÉBRARD, Jean. O autodidatismo exemplar. Como Valentin Jamerey-Duval aprendeu a ler? In: CHARTIER, Roger. Práticas da leitura. São Paulo: Estação Liberdade, 1996. 
Pedro da Silva Quaresma, os livros e revistas não eram objetos estranhos ao universo das crianças; ao contrário, tornaram-se mesmo familiares. A representação da leitura de Sebastião como arte mágica remete, desse modo, não só ao que o mundo adulto professava sobre a leitura infantil, mas às práticas e representações da leitura partilhadas pelas próprias crianças. Esse foi, se não o único, ao menos o mais importante paradigma de leitura.

Devemos, enfim, considerar que os contos folclóricos dos quais saíram as histórias de fadas havia muito no Brasil fizeram da voz das pretas velhas e governantas estrangeiras os mais preciosos livros. Com a difusão dessas histórias de domínio popular nas páginas do Tico-Tico, ou no repertório infantil da Livraria do Povo, a forma oral das narrativas encontrou um feitio escrito. Essa transformação formal explica-se pela circulação do escrito em uma conjuntura intelectual específica, em que a estratégia comercial dos editores na formação de um mercado de massas para os livros brasileiros apostava mais nos ouvintes do que em leitores.

Resumo: Este artigo tem como objetivo traçar o percurso que possibilita a passagem da história da edição a uma história da produção literária infantil brasileira. A preocupação com a definição do gênero relacionado às classes de idade foi, antes de tudo, tarefa dos livreiros-editores. Eram eles que classificavam e distribuíam os textos, organizando-os em coleções. Nessa perspectiva, o artigo analisa o circuito da produção, circulação e leitura dos livros da Biblioteca Infantil Quaresma.

Palavras-chaves: livros infantis, literatura infantil, mercado editorial, nacionalismo.
Abstract: The present paper aims to draw the courses that enable the passage from edition's history to Brazilian children's literary production history. The concern with gender definition engaged with ages was, first, a task for wholesale booksellers. They classified and distributed texts, organizing them into collections. From this viewpoint, the paper analyses books' production, circulation, and reading circuit of Quaresma Children's Library.

Keywords: children's books, children's literature, editorial market, nationalism. 